Andri Yunas Suryana,

PERAN AMIR MACHMUD DALAM PELAKSANAAN PEPERA 1969

\title{
PERAN AMIR MACHMUD DALAM PELAKSANAAN PEPERA 1969
}

\author{
Oleh: \\ Andri Yunas Suryana, Suwirta dan Moch. Eryk kamsori ${ }^{1}$
}

\begin{abstract}
This research entitled as "Peranan Amir Machmud dalam Mempertahankan Pemerintahan Soeharto 1969-1982". The main problem in this research is "How deep the role of Amir Machmud in maintaining Soeharto's government 1969-1982?”. The hictorical method used in this research, that is consisting heuristic, critical sources, interpretation, and historiography. To deepen the analysis, the interdisipliner approach such as sociology and political science was used in this research, such as role, political stability, and general elections concepts also there was Patron-Client and Structuration theories. Amir Machmud was a prominent figure during Orde Baru period. Amir Machmud was born at Cibeber, Cimahi city and had successful military career during New Order era. Amir Machmud held position as minister of domestic affairs in 3 periods. As a minister, he had successfully carry on some urge problems to government, like PEPERA problem that considered as fraudulence because unappropriate based on New York agreement by international affairs.
\end{abstract}

Keywords: Amir Machmud, Role, West Irian, PEPERA.

\section{PENDAHULUAN}

Setelah Irian Baratkembalikepangkuan Negara Kesatuan Republik Indonesia yaitu melalui penyerahan kedaulatan dari pemerintah Negara Kerajaan Belanda kepada Republik Indonesia pada tanggal 1 Mei 1963 dengan melalui suatu badan Perserikatan Bangsa-Bangsa (PBB) bernama United Nations Temporary Executive Authority (UNTEA) (Djopari, 1993: 1). Hal ini merupakan tujuan dari TRIKORA yang dikumandangkan oleh Presiden Soekarno di Alun-alun utara Yogyakarta pada tanggal 19 Desember 1961. TRIKORA ini merupakan suatu komando untuk menggagalkan pembentukan Negara

Papua yang dipersiapkan oleh Belanda. Isi dari TRIKORA yaitu, Gagalkan Negara Papua, Kibarkan bendera Merah Putih dan menjalankan mobilitas umum (Pigay, 2000: 222).

Setelah menyelesaikan masalahmasalah dalam negeri, militer Indonesia kembali dihadapkan kepada suatu permasalahan besar. Permasalahan Irian Barat yang tidak kunjung selesai kembali timbul. Kali ini Pemerintah Republik Indonesia secara tegas menginginkan adanya penyerahan atas Irian Barat dari Kerajaan Belanda. Dalam usahanya Presiden Soekarno berulang kali membawa

${ }^{1}$ Penulis adalah mahasiswa Pendidikan Sejarah FPIPS UPI, Suwirta sebagai pembimbing I dan Moch. Eryk Kamsori sebagai pembimbing II, penulis dapat dihubungi no hp 081323108885 atau email yunassuryana@gmail.com 
masalah Irian Barat ini ke PBB. Namun, Presiden Soekarno tidak mendapat tanggapan yang serius mengenai Irian Barat ini.Setelah dikumandangkannyaTRIKORA pada 19 Desember 1961 Republik Indonesia membentuk suatu komando tertinggi untuk mencegah terbentuknya Negara Papua. Kolonel Soeharto dipromosikan menjadi Jenderal dan ditunjuk sebagai panglima Mandala untuk pembebasan Irian Barat yang disebut Operasi Mandala (Osborne, 2001: 56). Operasi Mandala yang dipimpin oleh Jenderal Soeharto memiliki kantor pusat komando operasi di Makasar Sulawesi. Rencana Jenderal Soeharto adalah menyusup ke wilayah Papua Barat untuk menghancurkan dan mengusir paksa kekuatan musuh.

Operasi Mandala telah siap dengan beberapa rencana tetapi, yang paling mendesak adalah penyusunan gabungan tentara baik Angkatan Darat (AD), Angkatan Udara (AU), dan Angkatan Laut (AL). Hal ini dilakukan dalam rangka integrasi pasukan, membangun pangkalanpangkalan perang, mempelajari keadaan medan perang dan mempelajari kekuatan Belanda (Pigay, 2000: 225). Jenderal Soeharto selaku pimpinan Komando Mandala telah mempersiapkan beberapa Operasi untuk menggempur Belanda di irian Barat. Operasi-operasi tersebut seperti:
A. Operasi Banteng
B. Operasi Garuda
C. Operasi Srigala
D. Operasi Naga
E. Operasi Lumba-lumba
F. Operasi Jayawijaya

Amir Machmud yang menjabat sebagai Kolonel Infantri staf gabungan
II bertugas untuk mempersiapkan setiap penerjunan pasukan dalam setiap operasi yang dilaksanakan. Para penerjun ini mendapatkan tugas untuk menyiapkan tempat-tempat pendaratan bagi suatu penyerbuan dan membina masyarakat setempat (Machmud, 1987: 153). Dalam persiapan melaksanakan Operasi Jayawijaya, Kerajaan Belanda secara menyelesaikan permasalaha Irian Barat ini secara diplomasi. Atas saran dari Amerika Serikat, Akhirnya pada tanggal 15 Agustus 1962 di New York, Amerika Serikat tercapai suatu kesepakatan yang disebut New York Agreement. Perjanjian antara Republik Indonesia dan Kerajaan Belanda ini berisikan tiga poin penting. Yaitu, Pertama pemerintahan atas Irian Barat harus diserahkan kepada Republik Indonesia melalui badan PBB yaitu UNTEA. Kedua, terhitung 1 Mei 1963 UNTEA menyerahkan tanggungjawabadministrasipemerintahan di Irian Barat kepada Republik Indonesia. Ketiga, pada akhir tahun 1969 dibawah pengawasan PBB dilakukan Act of Free Choice (PEPERA) (Pigay, 2000: 243).

Dalam usaha menjalankan Act of Free Choice atau yang lebih dikenal dengan PEPERA, Pemerintah Indonesia mempersiapkan segalanya agar dapat berjalan dengan baik. Mendagri yang mendapat tugas untuk melaksanakan PEPERA ini mempersiapkan semuanya. Amir Machmud yang menjabat sebagai Mendagri menggantikan Basuki Rachmat karena meninggal dunia mendapatkan tugas dari Presiden Soeharto dalam pidato pelantikannya mengenai PEPERA. Menurutnya PEPERA merupakan salah satu dari kewajiban internasional Republik Indonesia. Namun, Presiden Soeharto berpesan agar PEPERA jangan sampai gagal. Artinya harus diusahakan jangan 
Andri Yunas Suryana,

PERAN AMIR MACHMUD DALAM PELAKSANAAN PEPERA 1969

sampai wilayah Irian Barat terlepas lagi dari Kesatuan Republik Indonesia (Machmud, 1987: 334). Maka untuk mensukseskan dan menjalankan perintah ini Amir Machmud melakukan persiapan-persiapan secara struktural dan juga non struktural.

\section{METODE PENELITIAN}

Metode penelitian yang digunakan dalam skripsi ini adalah metode historis. Metode ini digunakan oleh peneliti karena penelitian ini merupakan kajian sejarah yang data-datanya diperoleh dari jejak-jejak yang ditinggalkan dari suatu peristiwa masa lampau. Metode historis menurut Gottschalk (1986: 32) adalah proses menguji dan menganalisis secara kritis rekaman dan peninggalan, kemudian menuliskannya berdasarkan fakta yang diperoleh. Sedangkan menurut Ismaun (2005: 34), metode historis terdiri dari empat langkah yaitu heuristik (pengumpulan sumber), kritik (kritik eksternal dan internal), interpretasi (penafsiran) dan historiografi.

Pada tahap heuristik, peneliti melakukan pencarian sumber mengenai permasalahan yang dikaji di beberapa perpustakaan seperti perpustakaan Universitas Pendidikan Indonesia,perpustakaanJurusanPendidikan Sejarah, perpustakaan Museum Konfrensi Asia-Afrika, perpustakaan Batoe Api, Perpustakaan Nasional Republik Indonesia, serta beberapa perpustakaan Universitas lainnya yaitu perpustakaan Universitas Parahyangan dan perpustakaan Universitas Padjadjaran. Untuk pencarian sumbersumber yang relevan di internet, peneliti mencari beberapa jurnal ataupun artikel dari beberapa website.
Setelah melakukan heuristik, peneliti melakukan kritik. Kritik dilakukan dengan tujuan untuk meminimalisir subjektivitas dalam penulisan sejarah. Peneliti melakukan kritik eksternal terhadap sumber-sumber buku yang didapatkan pada tahap heuristik. Kritik eksternal ialah cara melakukan verifikasi atau pengujian terhadap aspek-aspek "luar" dari sumber sejarah (Sjamsuddin, 2007: 132). Peneliti menemukan sumber primer yaitu Buku Otobiografi Amir Machmud Prajurit Pejuang. kritik eksternal yaitu sumber yang diklasifikasikan harus otentik dalam artian berada dalam periode yang sezaman dengan apa yang diteliti serta merupakan perintah langsung dari Presiden Indonesia pada saat itu yaitu Soeharto. Otentik yang dimaksud disini ialah bahwa sumber tersebut dapat melaporkan dengan benar mengenai sesuatu subjek yang tampaknya benar.

Setelah melakukan kritik eksternal, penelitimelakukan kritikinternal. Menurut Sjamsuddin (2007: 143) kritik internal menekankan aspek "dalam", yaitu isi dari sumber kesaksian (testimoni). Peneliti melakukan kritik internal terhadap bukubuku yang memaparkan mengenai Peranan Amir Machmud dalam Pemerintahan Orde Baru. Semua buku tersebut memaparkan hal yang berbeda dan memiliki sudut pandang yang berbeda, yang membedakan dari materi dan kejelasan yang dipaparkan. MisalnyabukuOtoBiografiAmurMachmud prajurit Pejuang yang memaparkan mengenai jejak langkah perjalanan karir serta kehidupan Amir Machmud. SedangkanbukuAmir MachmudMenjawab menjelaskan mengenai tindakan-tindakan yang dilakukan oleh Amir Machmud yang dianggap kontroversi. 
Selanjutnya adalah tahap interpretasi. Dari semua fakta-fakta yang ada sangat jelas bahwa peran dari Amir Machmud dalam mempertahankan pemerintahan Soeharto sangatlah besar. Terlebih lagi Amir Machmud mengeluarkan beberapa kebijakan yang dianggap sangap menguntungkan Orde Baru.

\section{HASIL PENELITIAN DAN PEMBAHASAN}

Berdasarkan perjanjian New Yorkpada tanggal 15 Agustus 1962, Secara resmi pemerintah Belanda menyerahkan kekuasaannya terhadap Irian Barat kepada pemerintah Republik Indonesia melalui badan PBB yaitu UNTEA. Adapun isi perjanjian tersebut menyebutkan bahwa secararesmipadatanggal1Mei1963UNTEA menyerahkan kekuasaan atas Irian Barat kepada Indonesia. Pemerintah Indonesia diwajibkan untuk menyelenggarakan Act of Free Choice atau PEPERA bagi orang untuk dapat bergabung dengan Indonesia atau menentukan nasibnya sendiri (Pigay, 2000: 244). Namun, pelaksanaan PEPERA harus berada dalam pengawasan PBB. Dengan beralihnya kekuasaan atas Irian Barat dari UNTEA kepada Indonesia maka pemerintah mengambil berbagai kebijakan yang bersifat politis. Tindakanini dilakukan untuk memudahkan sensus secara administratif di Irian Barat. Pemerintah Indonesia dapat menjalankan kebijakan Presiden Soekarno yang keluarkan pada tahun 1962 mengenai pembentukan Provinsi Irian Barat gaya baru. Hal ini dirumuskan dalam Penetapan Presiden No. 1/1962 mengenai pembentukan Provinsi Irian Barat dengan ibukota Jayapura (Poesponegoro \& Notosusanto, 1993: 336). Dengan terbentuknya struktur administratif di Irian Barat akan memudahkan Amir Machmud selaku Mendagri dalam pelaksanaan PEPERA.

Dengan kembalinya Papua Barat atau Irian Barat kepangkuan bumi pertiwi, maka seluruh sistem politik dan perundangundangan Republik Indonesia berlaku di Irian Barat. Provinsi Irian Barat dibentuk dengan seorang putra daerah Frans Kaiseppo sebagai Gubernur pertamanya. DPR-GR tingkat I dan tingkat II dibentuk dan sistem kepartaian Indonesia meluas sampai ke Irian Barat (Machmud, 1987: 334). Namun, dalam menjalankan roda pemerintahannya dikontrol sepenuhnya dari militer, dikoordinasikan oleh Wakil Perdana Menteri Pertama Koodinator Irian Barat (WAMPA IRBAR) yang merupakan salah satu unsur komando pembebasan Irian Barat. Gubernur diberikan kepada seorang warga sipil akan tetapi, ia tidak berdaya melakukan kebijakannya. Hal ini karena menurut Inpres No.2/1963-Rahasta Bab III pasal 2 ayat 7, yang menyebutkan bahwa Gubernur dibantu oleh dewan pembantu dan penasehat yang terdiri dari Angkatan Darat, Angkatan Laut, Angkatan Udara dan dinas lainnya (Pigay, 2000: 259). Maka peranan dari Gubernur di Irian Barat dapat dikatakan tidak memiliki fungsi sebagai mana mestinya. Karena Gubernur tidak dapat mengeluarkan kebijakan tersendiri, tetapi harus setujui oleh dewan pembantu dan penasehatnya. Dapat dikatakan pula bahwa Gubernur di Irian Barat ini hanya dijadikan sebagai "boneka politik" untuk menarik simpati dari rakyat Irian Barat.

Sejak menerima tugas melaksanakan PEPERA, Amir Machmud tidak pernah mempertanyakan status Irian Barat. Menurutnya masalahnya jelas, wilayah itu telah menjadi bagian dari Republik Indonesia dan akan tetap demikian. Hal 
Andri Yunas Suryana,

PERAN AMIR MACHMUD DALAM PELAKSANAAN PEPERA 1969

ini dikarenakan Amir machmud dalam menyusun program-programnya PEPERA yang senantiasa memikirkan kemungkinan terburuk.Yaitubagaimanadantindakanapa yang akan dilakukan kalau mayoritas rakyat Irian Barat memilih untuk melepaskan diri dari Indonesia. Bagi Amir Machmud dan pemerintah Orde baru tidak ada pilihan lain. Maka Irian Barat harus tetap dalam pangkuan Ibu Pertiwi (Machmud, 1987: 334). Pemerintah Orde Baru merasa bahwa pelaksanaan PEPERA merupakan sesuatu yang tidak perlu dilakukan karena sudah pasti Irian Barat akan ikut dengan Indonesia. Hal ini ditanggapi lebih serius oleh dunia internasional. PBB menganggap Indonesia tidak pernah merencanakan mengenai masa depan Irian Barat. Pada tanggal 1 April 1968, duta besat Bolivia untuk PBB Fernando Ortiz-Sanz terkejut karena mendapati bahwa Indonesia tidak pernah berniat membicarakan masa depan dari Papua Barat atau Irian Jaya. OrtizSanz merupakan orang yang bertugas untuk mengawasi tahap akhir pemungutan suara PEPERA (Osborne, 2001: 87). Duta besar Republik Indonesia di PBB Sudjarwo tidak menyukai langkah yang diambil oleh Amir Machmud. Menurut Sudjarwo pelaksanaan PEPERA perlu dilakukan dan diikut sertakannya PBB sebagai badan pengawas jalannya PEPERA dengan OrtizSanz sebagai utusan PBB.

Dengan berbagai kritik yang terus berdatangan kepada Amir Machmud, maka sejak tahun 1969 Amir Machmud menjadikan PEPERA ini sebagai agenda utama. Presiden Soeharto menekankan bahwa memang ada kelainan dan kekhususan sampai sekarang mengenai Irian Jaya dalam pengertian prioritas dan anggarannya. Karena patut mendapat anggaran dan kebijakan khusus.
Pelaksanaannya Presiden Soeharto serahkan kepada Menteri Dalam Negeri. Irian Barat mesti bisa menikmati kemerdekaannya (Dwipayana \& Ramadhan K.H, 1989: 110). Hal ini merupakan sebuah tugas yang secara langsung diberikan oleh Presiden Soeharto kepada Mendagri untuk memperhatikan masalah PEPERA. Berawal dari Undang-Undang Nomor 12 Tahun 1969 dibentuklah provinsi otonom Irian barat dan Kabupaten-kabupaten otonom di Irian Barat. Sebagai tindak lanjut dari Undang-Undang tersebut maka pemerintahannya diatur dalam peraturan Menteri Dalam Negeri Nomor 9 Tahun 1969 tentang pelaksanaan pemerintah provinsi Irian Barat dan kabupatenkabupaten di Irian Barat. Serta diatur pula tentang Struktur Organisasi dan Tata Kerja Pemerintahan Provinsi Irian Barat dalam peraturan Menteri Dalam Negeri Nomor 10 Tahun 1969 (Djopari, 1993: 62-63). Peratuan menteri ini memberikan kesempatan kepada rakyat Irian Barat untuk mengembangkan diri sebagai daerah otonom yang memisahkan kepentingan pusat pemerintahan dan kepentingan daerah otonom. Dengan berubahnya Provinsi Irian Barat menjadi daerah otonom, maka mulai sedikit demi sedikit terlepas dari cengkraman militer. Namun pemahaman mengenai Pancasila telah diterapkan dengan baik oleh pihak militer di Irian Barat. Penempatan DPRGR tingkat I dan tingkat II juga merupakan orang-orang yang dipilih oleh pemerintah dan dianggap pro terhadap pemerintah Republik Indonesia. Hal ini dilakukan sebagai usaha mensukseskan pelaksanaan PEPERA.

Bersama dengan DPR-GR tingkat I dan tingkat II di Iran Barat Amir Machmud membentuk suatu Dewan Musyawarah 
PEPERA (DMP) untuk melaksanakan PEPERA. Seperti yang telah diungkapkan oleh Presiden Soeharto bahwa perlu kiranya melibatkan kepala suku, tokoh masyarakat serta unsur-unsur politik dan pemerintah dalam pelaksanaan PEPERA. Maka DMP ini beranggotakan berbagai unsur tersebut dengan jumlah anggota sebagai berikut, Merauke 175 orang, Wamena 175 orang, Nabire/Paniai 75 orang-FakFak 75 orang, Sorong 110, Manokwari 75 orang, Biak 130 orang dan Jayapura 110 orang. Pembentukan keanggotaan DMP ini ditargetkan selesai pada Juli 1969 (Machmud, 1987: 335). Sebelum berangkat ke Irian Barat untuk memeriksa persiapan pelaksanaan PEPERA dan pembentukan DMP ini Amir Machmud bertemu dengan Presiden Soeharto untuk melaporkan seluruh persiapan yang telah dilakukan. namun, dalam pelaksanaan persiapan PEPERA ini tidak berjalan dengan mulus. Terdapat berbagai pemberontakan untuk mengagalkan pelaksanaan PEPERA. Serta muncul dan berkembangnya keinginan untuk membentuk Negara Papua merdeka oleh segelintir orang yang dinamakan Organisasi Papua Merdeka (OPM). Nama OPM ini diberikan oleh pemerintah Indonesia kepada setiap organisasi atau faksi baik di Irian Jaya maupun diluar negeri yang dipimpin oleh putra-putra Irian Jaya pro-Papua Barat dengan tujuan memisahkan atau memerdekakan Irian Jaya yang pertama kali dilakukan di Manokwari tahun 1964 (Djopari, 1993: 100). Kebanyakan pemimpin Organisasi Papua Merdeka ini merupakan para kader-kader Belanda yang dibentuk untuk mendeklarasikan negara boneka Papua barat. Para kader-kader ini dibentuk dan dibina sebelum Operasi mandala dilaksanakan oleh pemerintah Republik Indonesia.

Dalam upaya untuk mensukseskan pelaksanaan PEPERA pemerintah Indonesia bersama TNI melakukan sebuah pengamanan terhadap protes yang terjadi dimana-dimana. Hal ini dikarenakan menguatnya nasionalisme Papua telah lama ditanamkan oleh pemerintah Belanda. Karena dirasa membahayakan jalannya pelaksanaan PEPERA, menurut Pigay dalam bukunya Evolusi Nasionalisme dan Sejarah: Konflik Politik di Papua, menyatakan bahwa:

"Dalam upaya menyukseskan Penentuan Pendapat Rakyat (PEPERA) yang akan dilaksanakan tahun 1969, maka Operasi Wibawa ini berusaha keras untuk menghabiskan sisa-sisa OPM terutama pimpinan Ferry Awom yang dianggap dapat menggagalkan keleluasaan Indonesia dalam mengintegrasikan Irian. Operasi inilah yang menyukseskan PEPERA dengan cara menyiapkan dan memberikan pengarahan-pengarahan kepada setiap anggota Dewan Musyawarah PEPERA. Sampai selesai pelaksanaan PEPERA, Operasi dari Sarwo Edhi Wibowo belum berhasil mematahkan perjuangan OPM pimpinan Ferry Awom (2000: 266).”

Operasi Wibawa yang dilakukan oleh Brigjen Edhi ini memberikan dampak baik bagi pelaksanaan PEPERA. Meskipun Operasi ini tidak dapat menghentikan perjuangan OPM pimpinan Ferry Awom. Tindakan Brigjen Edhi dengan mengerahkan pasukan KODAM Cendrawasi ini merupakan sebuah antisipasi dari setiap gerakan lain yang dilakukan oleh OPM pimpinan masa lainnya. Karena dalam masa persiapan PEPERA ini terjadi berbagai demonstrasi 


\section{Andri Yunas Suryana, \\ PERAN AMIR MACHMUD DALAM PELAKSANAAN PEPERA 1969}

yang menentang pelaksanaan PEPERA karena sistemnya yang tidak sesuai dengan hukum internasional.

Dalam pelaksanaan PEPERA 1969 pemerintah Indonesia dibantu atau diawasi oleh PBB sesuai dengan isi Perjanjian New York. Sekertaris Jenderal PBB U. Thant mengutus wakilnya ke Irian Barat dalam upayanya merealisasikan isi pasal 18 dan 20 Perjanjian New York. Dr, Ortiz-Sanz seorang Duta Besar dari Bolivia dikirim untuk mengatur jalannya PEPERA (Pigay, 2001: 277). Namun, Ortiz-Sanz tidak melakukan persiapan secara maksimal untuk pelaksanaan PEPERA. Ortiz-Sanz menyerahkankepadapemerintahIndonesia untuk menyusun mekasnisme pelaksanaan PEPERA. Ortiz-Sanz sering kali dipandang negative serta dianggap sebagai orang yang tidak tegas. Bahkan terkadang dianggap berkomplot dengan cara-cara yang dipakai Indonesia dalam melegitimasi pengambil alihan suara Penentuan Pendapat Rakyat (Osborne, 2001: 83). Sikap Ortiz-San ini dirasa oleh pemerintah Indonesia sebagai pendukung kesuksesan dari Pelaksanaan PEPERA. PBB yang menunjuk OrtizSanz bersama 50 anggotanya tidak dapat datang seluruhnya. Hal ini dikarenakan permintaan dari pemerintah Indonesia untuk mengurangi jumlah pengawas PBB guna meminimalisir dana pelaksanaan PEPERA ini. Maka PBB hanya mengutus Ortiz-Sanz bersama 16 anggotanya yang telah dipangkas sebelumnya.

Sebelum pelaksanaan PEPERA, pemerintah Indonesia mengajukan penggantian mekanisme dari PEPERA kepada PBB. Persiapan pengambilan data, pendataan dan perlengkapan dan tata cara PEPERA mulai tahun dilaksanakan tahun 1968. Pelaksanaan PEPERA yang semula menghendaki PEPERA dilakukan bagi semua orang dewasa baik pria maupun wanita sengan sistem "One Man, One Vote" (Satu orang, satu suara) sesuai dengan pendekatan internasional. Tetapi, Indonesia mengiginkan PEPERA dilaksanakan dengan "Many Man, One Vote" banyak orang satu suara atau sesuai dengan sistem yang dianut Indonesia musyawarah mufakat atas dasar Pancasila. Indonesia memberikan alasan bahwa pendekatan internasional tidak sesuai dengan budaya Indonesia (Pigay, 2001: 277-278). Hal ini ditanggapi oleh berbagai pihak baik dari masyarakat Irian Barat dan juga dari dunia internasional. Masyarakat Irian Barat melakukan demonstrasi ke kediaman Ortiz-Sanz sebgai perwakilan PBB untuk menyampaikan aspirasinya. Isi dari tuntutannya adalah menuntut penyelenggaraan pemilihan PEPERA tahun1969 tidak dengan cara musyawarah. Tetapi harus sesuai dengan ketentuan Perjanjian New York yaitu dengan cara One Man, One Votei atau setiap orang datang dan memberikan suara (Usman \& Din, 2010: 118). Aksi dari demonstran ini disampaikan oleh Ortiz-Sanz kepada Sekretaris Jenderal PBB U. Thant. Namun, tuntutan dari masyarakat Irian Barat ini ditolak dan U. Thant lebih menghendaki pendekatan yang diusulkan oleh Indonesia dengan jalan musyawarah sesuai dengan Pancasila.

Pelaksanaan PEPERA pertama kali dilakukan di Merauke pada tanggal 14 Juni 1969. Sidang Dewan Musyawarah PEPERA berlangsung tertib. Dalam setiap sidang Dewan Musyawarah PEPERA yang berbicara adalah ketuan DMP, Gubernur Irian Barat, Sudjarwo Tjondronegoro, SH., Perwakilan PBB dan Mendagri. Setelah mendengar keputusan 
berbagai pihak, maka keputusan diambil. Merauke tetap dalam wilayah Republik Indonesia dan ini merupakan kemenangan pertama. Kemudian menyusul Kabupaten Jayawijaya pada tanggal 16 Juli 1969 (Machmud, 1987: 337). Kabupaten Merauke yang berpenduduk 144.171 jiwa diwakili oleh 175 anggota DMP dalam pelaksanaan PEPERA. Sedangkan, Kabupaten Jayawijaya yang berpenduduk 165.00o diwakili oleh 175 anggota DMP juga. Dalam setiap persidangan DMP sepenuhnya dilaksanakan oleh pemerintah Indonesia sedangkan utusan PBB hanya mengawasi jalannya PEPERA. Dalam setiap kesempatan sebelum dimulainya PEPERA selalu disertai dengan ajakanajakan dari Gubernur Frans Kaisepo yang pada saat itu ditunjuk sebagai kepala pemerintahan Komando Proyek XII Irian Barat untuk PEPERA. Isi ajakan adalah memilih untuk tetap bersatu dengan Negara Republik Indonesia (Pigay, 2001, 279-280). Tindakan yang diambil oleh Gubernur ini merupakan penyelewengan terhadap hukum internasional. Serta dianggap telah melanggar kebebasan dalam menyampaikan pendapat yang tercantum dalam Perjanjian New York.

Pelaksanaan PEPERA berlanjut ke Kabupaten Piniai pada tanggal 19 Juli 1969, Kabupaten Fak-Fak 23 Juli 1969, Kabupaten Sorong tanggal 26 Juli, Kabupaten Manokwari tanggal 29 Juli 1969, Kabupaten Cenderawasi 31 juli 1969 dan diakhiri pada tanggal 2 Agustus 1969. Dalam setiap sidang DMP, muncul pandangan-pandangan yang dikemukakan oleh sejumlah anggota DMP. Salah seorang pejuang Irian Barat yang tidak asing lagi, yaitu Lukas Rumkorem menyatakan bahwa setiap Kabupaten di Irian Barat adalah daerah perjuangan. Maka dengan ini secara singkat saya bentangkan dihadapan misi tuan Ortiz-Sans. Irian Barat adalah hak mutlak Negara Republik Indonesia yang berwilayah dari Sabang sampai Merauke (Machmud, 1987: 337-338). Dalam setiap sidang DMP yang dilakukan dinyatakan berhasil mempertahankan Irian Barat tetap kedalam bagian dari Negara Kesatuan Republik Indonesia. Namun, pelaksanaan PEPERA ini mendapatkan kritik yang sangat tajam dariberbagai pihak. Maneuver dari mendagri serta peran militer dalam usaha mensukseskan pelaksanaan PEPERA dianggap telah melanggar hukum internasional dan dianggap tidak mematuhi aturan yang tertera dalam Perjanjian New York. Menurut Socrates Sofyan Yoman, keterlibatan langsung aparat keamanan Indonesia memenangkan PEPERA 1969 dengan istilah Operasi Teritorial, Operasi Tempur, Pembinaan dan pembentukan DMP. DMP singkatan dari Dewan Musyawarah PEPERA bentukan ABRI (kini TNI). Anggota DMP adalah orang-orang yang dipilih oleh ABRI dan pemerintah yang diawasi ketat dibawah intimidasi, terror dan ancaman pembunuhan hanya untuk menggabungkan Papua Barat secara paksa ke dalam wilayah Negara Republik Indonesia dengan PEPERA 1969 yang cacat moral, hukum dan tidak demokratis (Yoman, 2013: 67). Menurutnya pelaksanaan PEPERA tidak sesuai dengan hukum internasional dan terlalu banyak pelanggaran hukum dan HAM yang dilakukan oleh pemerintah Indonesia terutama panitia pelaksana PEPERA.

Meskipun mendapat kritik dari berbagai pihak, pelaksanaan PEPERA berjalan dengan lancar dan berhasil menyatukan Irian Barat tetap dalam bagian Negara Kesatuan Republik 
Andri Yunas Suryana,

PERAN AMIR MACHMUD DALAM PELAKSANAAN PEPERA 1969

Indonesia. Setelah pelaksanaan PEPERA selesai, Amir Machmud menyampaikan pidatonya didepan DPR-GR tingkat 1 Irian Barat di Jayapura pada 5 Agustus 1969. Amir Machmud menyampaikan tiga permasalahan menyangkut PEPERA ini. Pertama, Hasil Pelaksanaan PEPERA. Kedua, Follow Up dibidang Pemerintahan. Ketiga, Follow Up dibidang pembangunan (Machmud, 1987: 338). Dalam proses Follow up pada tanggal 8 Agustus 1969, Mendagri Amir Machmud yang bertindak sebagai ketua pelaksana PEPERA melaporkan kepada Presiden Soeharto mengenai hasil dari PEPERA. Dilanjutkan oleh Presiden Soeharto melaporkan hasil dari pelaksanaan PEPERA kepada MPRS (Pigay, 2001: 280). Dalam proses follow up ini pemerintah menetapkan Irian Barat sebagaidaerahotonomuntukmempercepat pembangunan di Irian Barat. Sejak Irian Barat berintegrasi dengan Indonesia secara resmi melalui PEPERA, dimulailah pembangunan yang lebih serius untuk menyelesaikan masalah sosial-ekonomi di Irian Barat.

Sesuai dengan kebijaksanaan pemerintahIndonesia,makasegeradisusun Rancangan Undang-Undang pembentukan Provinsi Otonom Irian Barat. Pada tanggal 16 Agustus 1969 dengan amanat Presiden Soeharto, disampaikan Rancangan Undang-Undang tersebut kepada DPR-GR untuk dibicarakan dan disahkan sebagai Undang-Undang. Amir Machmud secara pribadi mengirimkan surat kepada DPRGR untuk memprioritaskan pembicaraan mengenai Rancangan Undang-Undang dalam sidang DPR-GR. Maka diresmikan Undang-UndangtersebutmenjadiUndangUndang Nomor 12 Tahun 1969. Menurut Undang-Undang tersebut Provinsi Otonom Irian Barat dibagi menjadi 9 Kabupaten
(Machmud, 1987: 338-339). Pemerintah Indonesia menyiapkan 7proyekutamayang dilaksanakan dalam rangka pembangunan di Irian Barat dengan pembiayaan dari Pelita, penanaman modal asing dan kontrak-kontrak pertambangan di Irian Barat.

Pemerintah Indonesia melaksanakan 7 proyek pembangunan yaitu, pembangunan komunikasi, industri primer, pendidikan, listrik, kesehatan, pekerjaan umum dan perindustrian. Keadaan ekonomi yang merosot pada awal integrasi di Irian Jaya, kemudian dengan aktivitas pembangunan yang dibiayai oleh danadana dari Pelita, FUNDWI dan Task Force serta kemudian diintegrasikan ke dalam APBN, INPRES dan APBD (Djopari, 1993: 92). Pembangunan ini dilaksanankan secepatnya dengan tujuan mempercepat atau mengejar pembangunan di Irian Barat yang dianggap tertinggal. Mendagri yang mendapat wewenang dari DPR-GR untuk membentuk perangkat daerah di Irian Barat mengeluarkan sebuah kebijakan yang guna mengatur keuangan dan kemampuan daerah tersebut. Surat Keputusan Menteri Dalam Negeri No. 134 dan 135 tahun 1970 tentang pembentukan dinas otonom untuk daerah tingkat 1 Irian Barat terdiri dari Dinas Pendidikan dan Kebudayaan, Dinas Sosial, Dinas Kesehatan, Dinas Pekerjaan Umum, Dinas Kehutanan. Sedangkan rencana dari Pelita baru terlaksana setelah pelaksanaan PEPERA selesai (Pigay, 2001: 282).

Berintegrasinya Irian Barat kedalan Indonesia bukan berarti tidak memiliki cacat hukum. Masih banyak suara yang bersifat gugatan terhadap hasil dari PEPERA ini baik dari dalam negeri maupun luar negeri. Duta Besar Ghana, memprotes dalam sidang umum PBB berdasarkan 
hasil laporan dari Ortiz-Sanz tentang sikap Mendagri dan Pemerintah Indonesia kepada peserta PEPERA. Serta Duta Besar Gabon merasa kebingunan dengan sikap yang diambil oleh Mendagri dan Pemerintah Indonesia tentang metode dan prosedur yang dipakai untuk musyawarah (Yoman, 2013: 70). Dalam sidang umum PBB tersebut telah mengesahkan hasil dari PEPERA tersebut dengan jumlah suata 84 anggota PBB setuju dan 30 negara mengambil sikap abstain. 30 negara yang mengambil sikap abstain itu hampir semuanya berasal dari Afrika. Duta Besar Zambia menyatakan bahwa delegasi kami sampai sejauh ini tidak bisa mengerti mengapa perwakilan Sekjen PBB di Irian Jaya bersedia menyetujui bentuk pemungutan sura berdasarkan asas perundingan musyawarah dengan seribu tokoh terkemukan yang telah ditunjuk oleh pemerintah Indonesia. Sesuatu yang jelas tidak dapat diterapkan menurut kesepakatan dalam perjanjian sebenarnya (Osborne, 2000: 106). Gugatan-gugatan tersebut ditujukan kepada metode yang digunakan dalam pelaksanaan PEPERA yang dianggap tidak sesuai dengan hukum internasional. Serta perwakilan dari Afrika menganggap jika mereka menyetujui hasil dari PEPERA yang mereka anggap sebagai cacat hukum dapat memperlemah posisi PBB di Afrika dalam menghadapi masalah rezim minoritas kulit putih di Afrika Selatan.

Keberhasilan dari pelaksanaan PEPERA 1969 yang didapat oleh Indonesia ini menimbulkan berbagai dampak dari masyarakat baik dari luar negeri maupun dalam negeri. Reaksi muncul dari dunia Internasional terhadap pelaksanaan PEPERA tahun1969 di Irian Barat. Delegasi dari berbagai negara di PBB menganggap pelaksanaan PEPERA ini penuh dengan kecurangan dan dianggap tidak relevan dengan hukum Internasional. Secara tegas delegasi dari Zambia di PBB menyebutkan bahwa sampai sejauh inimereka tidak dapat mengerti mengapa perwakilan sekjen PBB di Irian Barat bersedia menyetujui bentuk pemungutan suara berdasarkan asas perundingan musyawarah dengan seribu tokoh terkemuka yang telah ditunjuk oleh pemerintah Indonesia. Tindakan ini merupakan suatu tindakan yang jelasjelas tidak dapat diterapkan menurut kesepakatan dalam perjanjian New York. Lebih tegas lagi delegasi dari Ghana di PBB menyatakan bahwa:

"kami tidak yakin bahwa prinsip-prinsip musyawarah adalah satu-satunya cara yang dapat dimengerti oleh penduduk wilayah tersebut. menurut kami bahwa dibawah pemerintahan administrasi Belanda sebuah sistem demokrasi yang dikenal sebagai Pemilihan Tertutup telah berhasil diterapkan lebih lanjut, di NuginiAustralia yang mempunyai karakteristik geografis yang sama sulitnya dan dihuni oleh kelompok masyarakat yang sama-sama disebut sebagai belum mahu, prinsip satu orang satu suara telah berhasil diterapkan dan hal ini pulalah yang mendukukng kebijakan yang diterapkan disana, yang pada akhirnya membawa masyarakat pada kekuasaan sendiri (Osborne, 2001: 106)."

Delegasi dari Ghana ini menganggap bahwa pemerintah Indonesia telah melakukan sebuah tindakan yang bertentangan dengan perjanjian New York. Pemerintah Indonesia dianggap telah menghilangkan hak dasar masyarakat Irian Barat. Delegasi dari Ghana juga merasa heran dengan tindakan dari perwakilan sekjen PBB untuk Irian Barat yang 


\section{Andri Yunas Suryana, \\ PERAN AMIR MACHMUD DALAM PELAKSANAAN PEPERA 1969}

menyetujui sistem pemilihan dengan jalan musyawarah yang tidak sesuai dengan isi perjanjian New York.

Tidak hanya dari luar negeri, masyarakat Papua Barat juga merasa bahwa sistem pemilihan secara musyawarah dianggap tidak sesuai dengan apa yang tertulis dalam perjanjian New York. Bahkan golongan masyarakat ini telah melakukan demonstrasi didepan kediaman dari perwakilan sekjen PBB untuk Irian Barat. Masyarakat Irian Barat menyampaikan resolusi kepada Ortiz selaku perwakilan dari sekjen PBB agar pelaksanaan PEPERA dilaksanakan dengan jalan demokrasi, yaitu "One Man, One Vote" (Pigay, 2001: 283). Masyarakat Papua merasa bahwa sistem ini akan lebih demokratis dibandingkan dengan jalan musyawarah. Terlebih lagi para anggota dewan permusyawaratan PEPERAditunjuk langsung oleh pemerintah Indonesia.

Namun, resolusi yang diberikan oleh masyarakat Irian Barat ini tidak diterima oleh Ortiz dan juga pemerintah Indonesia. Sistem pemungutan suara tetap menggunakan sistem musyawarah yang dianggap sesuai dengan Pancasila. Hal ini menimbulkan reaksi yang sangat ekstrim dari masyarakat Irian Barat. Banyak dari mereka yang melakukan pemberontakan secara fisik terhadap pemerintah Indonesia. Terlebih lagi hasil dari PEPERAyang menyatakan bahwa Irian Barat masuk kedalam bagian dari NKRI. Muncul berbagai aksi-aksi secara fisik untuk menentang PEPERA ini diberbagai daerah di Irian Barat, salah satunya terjadi di Manokwari pada tanggal 28 Juli 1965 sebelum pelaksanaan PEPERA. Pasukan dengan kekuatan kurang lebih 400 orang dengansenjataapiringancampuran,panah, kampak, parang dan tombak dibawah pimpinan Ferry Awom menyerang asrama Jonif 641 Cenderawasi I di Arfai (Djopari, 1993: 110). Tindakan lainnya juga terjadi setelah pelaksanaan PEPERA yang lebih terorganisir. Mereka yang tidak setuju dengan hasil dari PEPERA membentuk sebuah Organisasi Papua Merdeka.

OPM berhasil membentuk sebuah jaringan gerakan masa secara regional yang bertujuan untuk kemerdekaan Papua. Sebagaimana layaknya kelompokkelompok revolusioner di negara-negara lain, komando tersebut didominasi oleh kelompok elit yang terlatih pada masa koloniak sebelumnya. Seth Rumkorem adalah tokoh lain selain Ferry Awom yang memimpin pemberontakan di Papua. Seth Rumkorem yang pernah mendapat pendidikan militer Indonesia memimpin pemberontakan di wilayah perbatasan dan membentuk markas besar dengan nama Victoria (Osborne, 2001: 108-112). Di markas besar ini Seth Rumkorem mengorganisir semua pemberontakan-pemberontakan yang terjadi di Papua. Secara tegas juga Seth Rumkorem memproklamasikan kemerdekaan Papua di markas besar ini. Djopari menyebutkan dalam bukunya yang berjudul Pemberontakan Organisasi Papua Merdeka (1993: 116) bahwa:

Pada tanggal 1 Juli 1971 dari markas Victoria, Seth Rumkorem memproklamasikan Pemerintahan Papua Barat dengan naskah proklamasi sebagai berikut:

\section{PROKLAMASI}

"Kepada rakyat Papua sekalian, dari Numbay samapai Merauke, dari Sorong sampai Baliem (Pegunungan Bintang) dan 
dari Biak sampai pulau Adi. Dengan Berkat dan pertolongan Tuhan kami mendapatkan kesempatan hari ini, menyampaikan pada kamu sekalian berdasarkan keinginan luhur bangsa Papua, bahwa Bangsa dan Tanah Air Papua hari ini 1 Juli 1971, menjadi satu Bangsa dan Tanah Air yang merdeka dan berdaulat penuh. Kiranya Tuhan menyertai kita dan dengan ini dunia menjadi maklum, bahwa keinginan luhur Bangsa Papua untuk merdeka atas tanah airnya Papua Barat telah menjadi nyata. “

Victoria, 1 Juli 1971

Atas nama Rakyat dan Pemerintah

Papua Barat, Presiden,

Seth J. Rumkorem,

Brigadir Jenderal

Dengan dilaksanakannya Proklamasi kemerdekaan ini, Seth Rumkorem membentuk sebuah kabinet untuk menjalankan pemerintahannya. Namun, Proklamasi yang dilakukan oleh Seth Rumkorem merupakan sebuah pemberontakan dan tidak diakui oleh pemerintah Indonesia. Hal serupa juga pernah tejadi sebelumnya pada tahun1964, Ferry Awom secara tegas memproklamasikan kemerdekaan Papua di Sorong. Tindakan ini juga dianggap sebuah pemberontakan oleh pemerintah Indonesia.

Para anggota OPM melakukan pemberontakan secara fisik terhadap pemerintah Indonesia. Pada tahun 1972 untuk memperkuat eksistensi perjuangan OPM, maka di Merauke dibentuk beberapa organisasi gerakan kemerdekaan OPM yang bernama Gerakan Nasional Papua (Genapa), Natural Papua Nasional (Napan), Piagam Masyarakat Papua
Merdeka dan Santa Perawan Maria (SPM). Semua organisasi ini melakukan berbagai aktivitas menentang hasil dari PEPERA dengan menumbuhkan rasa nasionalisme Papua (Pigay, 2001: 204-205). Tindakantindakan pemberontakan di Irian Barat tidak hanya sampai disini saja. Pada tahun 1977 menjelang pemilihan umum terjadi suatu gejolak sosial atau pemberontakan OPM yang dipimpin oleh Alex Degey dan Matias Tabuni di Kabupaten Jayawijaya. Pemberontakan ini terus berlanjut sampai bulan April tahun 1978 (Djopari, 1993: 121).

Reaksi yang timbul dari hasil PEPERA inimenjadipermasalahan nasional danjuga Internasional. Hal ini dikarenakan banyak dari pemberontak OPM yang melarikan diri keluar negeri dan meminta pertolongan untuk perjuangan kemerdekaan Papua Barat. Seth Rumkorem salah satunya yang melarikan diri ke PNG untuk keamanan dan juga untuk meminta bantuan dari PNG yang dianggap memiliki kesamaan dalam hal budaya. PNG juga mendesak kepada pemerintah Australia agar menerima para pejuang OPM yang melarikan diri ke Australia. Serta pemerintah PNG mendesak agar Pemerintah Australia membantu secara fisik terhadap perjuangan OPM.

\section{SIMPULAN}

Latar belakang belakang pelaksanaan PEPERA 1969 merupakan hasil perjanjian New York antara Indonesia dan Belanda. Dalam pelaksanaan PEPERA ini Indonesia diwajibkan untuk melaksanaan sebuah pemungutan untuk memutuskan masa depan dari Irian Barat. Namun, Indonesia melakukan beberapa tindakan yang dianggap melanggar isi perjanjian New York. Salah satunya 
dalam sistem pemungutan suara yang semula menggunakan One man, One Vote diubah menjadi sistem musyawarah. Hal ini dilakukan karena Amir Machmud menganggap sistem tersebut tidak sesuai dengan budaya Indonesia. Musyawatah yang dianggap sesuai dengan nilai-nilai Pancasila dan karakter budaya Indonesia.

Pelaksanaan PEPERA diawasi oleh PBB yang menghasilkan Irian Barat tetap bergabung dalam Indonesia. Namun hal ini menimbulkan beberapa permasalahan baru. Munculnya pemberontakan yang dipimpin oleh Fery Awom dan Seth Rumkorem merupakan dampak dari pelaksanaan PEPERA yang dianggap tidak sesuai. Pemberontakan tersebut dikenal dengan nama OPM dan mendeklarasikan kemerdekaan atas Papua Barat oleh Seth Rumkorem. Tindakan pemberontakan ini terus dilakukan sampai saat ini.

\section{DAFTAR PUSTAKA}

Djopari, J. (1993). Pemberontakan Organisasi Papua Merdeka. Jakarta: Resindo.

Dwipayana \& Ramadhan. (1989). Otobiografi Soeharto: Pikiran, Ucapan dan Tindakan Saya. Jakarta: PT Citra Lamtoro Gung Persada.

Gottschalk (1986). Mengerti Sejarah. Jakarta: UI Press.

Ismaun. (2005). Pengantar Belajar Sejarah Sebagai Ilmu Dan Wahana Pendidikan. Bandung: Historia Utama Press.

Machmud, A. (1987). Otobiografi Amir Machmud: Prajurit Pejuang. Jakarta: PT Rora Karya Offset.

Osborne, R (2001). Kibaran Sampari: Gerakan Pembebasan OPM dan Perang Rahasia di Papua Barat. Jakarta: ELSAM.

Pigay, D (2001). Evolusi Nasionalisme dan Sejarah: Konflik Politik di Papua. Jakarta: Pustaka Sinar Harapan.

Poesponegoro \& Notosusanto. (1993). Sejarah Nasional Indonesia VI. Jakarta: Balai Pustaka

Sjamsuddin, H. (2007). Metodologi Sejarah. Yogyakarta: Ombak.

Usman S. (2004). Sosiologi: Sejarah, Teori dan Metodelogi. Yogyakarta: Center for Indonesia Research and Development. 